\title{
NOTES
}

\section{Synthesis and Evaluation of a Carbazole Based Polymeric Azodye Containing Naphthalene Moiety}

\author{
Pradyot MiTRA and Mukul BISWAS* \\ Department of Chemistry, Indian Institute of Technology, \\ Kharagpur-721302, India
}

(Received May 23, 1989)

\begin{abstract}
KEY WORDS Polyazodye / Carbazole / Naphthalene / Thermal Stability /
Dielectric Constant / D.C. Conductivity /
\end{abstract}

During research on carbazole based copolycondensates $^{1}$ we observed that literature on carbazole based polymeric azodye systems, is meagre. Relevantly, polyazoarylenes have been explored in regard to their conductance behavior, ${ }^{2}$ while, Biswas and Das reported ${ }^{3}$ the synthesis of a polymeric azodye from carbazole and bisphenol-A and its thermal stability, dielectric and conductance characteristics. Interested to find out how the replacement of bisphenol-A by a condensed aromatic system such as naphthalene, with higher resonance stability and enhanced conjugation than benzene would influence the properties as above, we prepared and characterized a polymeric azodye from $N$-methylcarbazole-3,6diamine and 1,8-dihydroxy naphthalene-3,6disodium sulfonate. Our results highlighted in this article show that thermal stability, conductance, dielectric characteristics are considerably influenced by a change in the structure of the polymeric azodye.

\section{EXPERIMENTAL}

\section{Materials}

Carbazole (BDH) was recrystallized from the alcohol solution. 1,8-Dihydroxy-naphthalene-3,6-disodium sulfonate (Fluka AG), di- methyl sulfate $(\mathrm{BDH})$ were used as supplied.
Preparation of the Polymeric Azodye (CN- $P A D)(\mathrm{I})$

A mixture of $0.43 \mathrm{~g}(2 \mathrm{mmol})$ of $N$ methylcarbazole-3,6-diamine ${ }^{3} 4.2 \mathrm{ml}$ conc. $\mathrm{HCl}$ and $4.2 \mathrm{ml}$ water was kept at $0^{\circ} \mathrm{C}$ for $3 \mathrm{~h}$ with frequent shaking. To this, was added dropwise a cold solution of $1.6 \mathrm{~g}$ sodium nitrite in $8 \mathrm{ml}$ water for $30 \mathrm{~min}$ with vigorous stirring (at $0^{\circ} \mathrm{C}$ ) and the resulting diazonium salt solution was kept at $0^{\circ} \mathrm{C}$ for $3 \mathrm{~h}$ with constant stirring. The cold solution was added slowly to

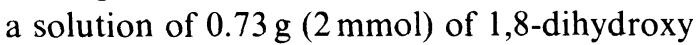
naphthalene-3,6-disodium sulfonate in $16 \mathrm{ml}$ of cold $10 \%$ aqueous sodium hydroxide for $30 \mathrm{~min}$ in an ice-salt bath with vigorous stirring, and kept at $0^{\circ} \mathrm{C}$ for $3 \mathrm{~h}$ with constant stirring. A dark violet compound separated out which was poured into $200 \mathrm{ml}$ ethanol with stirring, filtered, washed several times with dry ethanol and finally dried at room temperature, resulting in a dark violet polymeric azodye (yield 50\%). N\% 12.71 (calcd 12.65), S\% 14.08 (calcd 14.00), characteristic. IR absorption $\left(\mathrm{cm}^{-1}\right)(\mathrm{KBr}) 2200,1620(-\mathrm{N}=\mathrm{N}-$, strong bands), $1620(\mathrm{C}=\mathrm{C}$, aromatic stretching), $1200,1100,1030$ (strong bands for $-\mathrm{SO}_{3} \mathrm{H}$ group), 3400 (phenolic - $\mathrm{OH}$, stretching), 1380

\footnotetext{
* To whom all correspondence should be addressed
} 
phenolic $-\mathrm{OH}$, bending).

\section{Characterization}

Nitrogen was estimated by Micro-Dumas method $^{4}$ and sulfur by a standard procedure. The reduced viscosity of the polymeric azodye was measured in DMSO at a concentration of $0.5 \mathrm{~g} \mathrm{dl}^{-1}$ at $25^{\circ} \mathrm{C}$. IR spectra was recorded on a Perkin-Elmer 237B grating spectrophotometer. The magnetic susceptibility constant for CNPAD was determined by a Gouy balance. The thermal characteristics were studied with a Stanton Redcroft thermal analyzer at temperature upto $1100^{\circ} \mathrm{C}$ in static air $\left(10^{\circ} \mathrm{C} \mathrm{min}^{-1}\right)$. The dielectric constant and dielectric loss were measured by an Impedance Bridge (HP, A 4192) at room temperature. CNPAD was used as pellets (diameter $1.06 \mathrm{~cm}$, thickness $0.21 \mathrm{~cm}$ ) with silver coating on the surface. Conductivity versus temperature measurements were made by a 1666 DC Resistance Bridge (General Radio) with silver coated sample in the pellet form (diameter $1.03 \mathrm{~cm}$, thickness $0.21 \mathrm{~cm})$.

\section{RESULTS AND DISCUSSION}

The reduced viscosity of CNPAD in DMSO is $0.32 \mathrm{dlg}^{-1}$ which is of the same magnitude as the carbazole-bisphenol-A azodye (CBPAD). ${ }^{3}$

During magnetic measurements, CNPAD shows a weight difference of $-0.17 \times 10^{-3} \mathrm{~g}$ which implies that it is repelled by a magnetic field, a behavior typical of diamagnetic substances. The magnetic susceptibility constant was calculated to be $-0.35 \times 10^{-6}$ which compared with the value of $-0.45 \times 10^{-6}$ for CBPAD.

Like CBPAD, CNPAD develops different colors with acids (Table I), due to an internal salt formation stabilized by electron delocalisation. ${ }^{5}$ The deepening of the color may be atributed to resonance ${ }^{6}$ among charged canonical structures (Figure 1B). CNPAD also develops a deep red color with concentrated aqueous $\mathrm{NaOH}$ due to the formation of the
Table I. Characteristic chemical properties of CNPAD

\begin{tabular}{llll}
\hline \multicolumn{1}{c}{ Solvent } & Solubility & \multicolumn{1}{c}{ Color } & $\begin{array}{c}\text { Color on } \\
\text { large dilution } \\
\text { with water }\end{array}$ \\
\hline Organic solvents &,$+(\mathrm{DMSO})$ Deep violet & - \\
Conc. $\mathrm{HCl}$ & + & Yellow & Pale yellow \\
Conc. $\mathrm{H}_{2} \mathrm{SO}_{4}$ & + & Deep blue & Pale violet \\
Conc. $\mathrm{HNO}_{3}$ & + & Orange-red & Pale yellow \\
$\mathrm{HClO}_{4}$ & + & Blue & Pale violet \\
Aqueous $\mathrm{NaOH}$ & + & Violet & Pale violet \\
Ammonia solution & + & Red & Pale blue \\
\hline
\end{tabular}

(+ soluble).

A

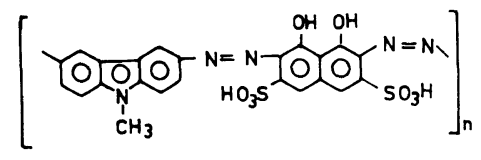

CNPAD

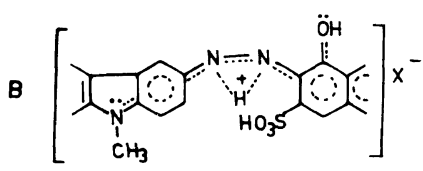

$X=\mathrm{HSO}_{4}, \mathrm{Cl}, \mathrm{NO}_{3}, \mathrm{ClO}_{4}$

Figure 1. A: Structure of CNPAD. Resonance structure of CNPAD in presence of acids.

sodium salt of CNPAD.

\section{Thermal Characteristics}

Figure 2 shows that CNPAD is initially stable upto $c a .150^{\circ} \mathrm{C}$ whereafter it looses weight upto ca. $12.5 \%$ at $160^{\circ} \mathrm{C}$. Further weight loss continues at a comparatively slower rate till $60 \%$ decomposition occurs at $700^{\circ} \mathrm{C}$, followed by a limiting weight loss of ca. $80 \%$ from $1000{ }^{\circ} \mathrm{C}$ onwards. The DTA curve displays an exothermic effect at $160^{\circ} \mathrm{C}$ $(12.5 \%)$ due to the disappearance of the azochromophore group implying the degradation of the polymer through cleavage of $-\mathrm{N}=\mathrm{N}$ bond. The IR spectrum of the product obtained from CNPAD by heating it upto $160^{\circ} \mathrm{C}$ shows the disappearance of azo-group absorption band at 2200 and $1620 \mathrm{~cm}^{-1}$. The DTA 


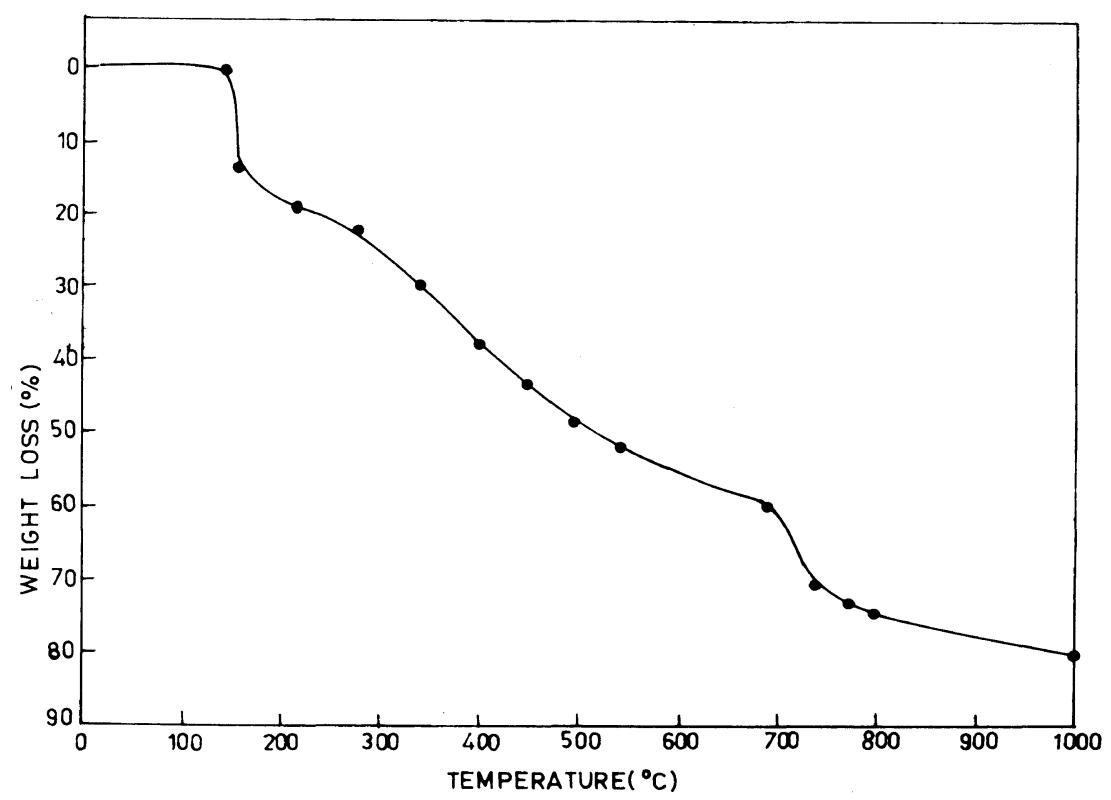

Figure 2. Thermogram of CNPAD.

Table II. Comparison of thermal characteristics of CNPAD and CBPAD

\begin{tabular}{|c|c|c|c|c|}
\hline \multirow{2}{*}{$\frac{\text { Temperature }}{{ }^{\circ} \mathrm{C}}$} & \multicolumn{2}{|c|}{ Weight loss $/ \%$} & \multicolumn{2}{|c|}{ DTA characteristics } \\
\hline & CNPAD & CBPAD & CNPAD & CBPAD \\
\hline 160 & 12.5 & 11.4 & Small exotherm & Small exotherm \\
\hline 40 & 38.0 & 33.0 & Exotherm & Exotherm (peak at $370^{\circ}$ ) \\
\hline 510 & 50.0 & 65.0 & Exotherm & 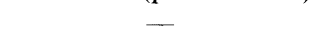 \\
\hline 755 & 73.0 & $\begin{array}{c}91.4 \\
\text { (constant from } 720^{\circ} \mathrm{C} \text { ) }\end{array}$ & Sharp exotherm & $\begin{array}{c}\text { A broad exotherm from } \\
370-720^{\circ}\end{array}$ \\
\hline
\end{tabular}

exothermic peaks at $400^{\circ} \mathrm{C}, 510^{\circ} \mathrm{C}$, and a very strong peak at $755^{\circ} \mathrm{C}$ signify destructive oxidation processes occurring in the intermediate compounds.

Table II shows that in general, CNPAD exhibits somewhat higher stability than CBPAD, apparently due to the presence of a condensed aromatic moiety in the chain.

\section{Dielectric Characteristics}

Figure 3 suggests that CNPAD possesses a high dielectric constant at low frequency, 94 at $10^{4} \mathrm{~Hz}$ which sharply falls to a limiting value of 14 at $10^{7} \mathrm{~Hz}$. Being a polar polymer with the preponderance of electro-negative elements as $\mathrm{N}, \mathrm{S}$, and $\mathrm{O}, \mathrm{CNPAD}$ undergoes asymmetric charge distribution giving rise to strong coupling in the electrical fields which are dependent on the applied frequency. ${ }^{7}$ CNPAD shows a consistent increase in $\tan \delta$ from 0.40 at $10^{4} \mathrm{~Hz}$ to a peak 0.60 at $10^{5.75} \mathrm{~Hz}$ and thereafter decreases sharply to 0.23 at frequency $10^{7.2} \mathrm{~Hz}$. Tan $\delta_{\max }$ occurring at $f=10^{10.6} \mathrm{~Hz}$ coincides with a corresponding inflection in the dielectric constant-frequency curve. This behavior is a typical of polar polymers exhibiting a dipole segmental loss and a dipole group loss. ${ }^{8}$ In CNPAD, intra/inter molecular hydrogen 


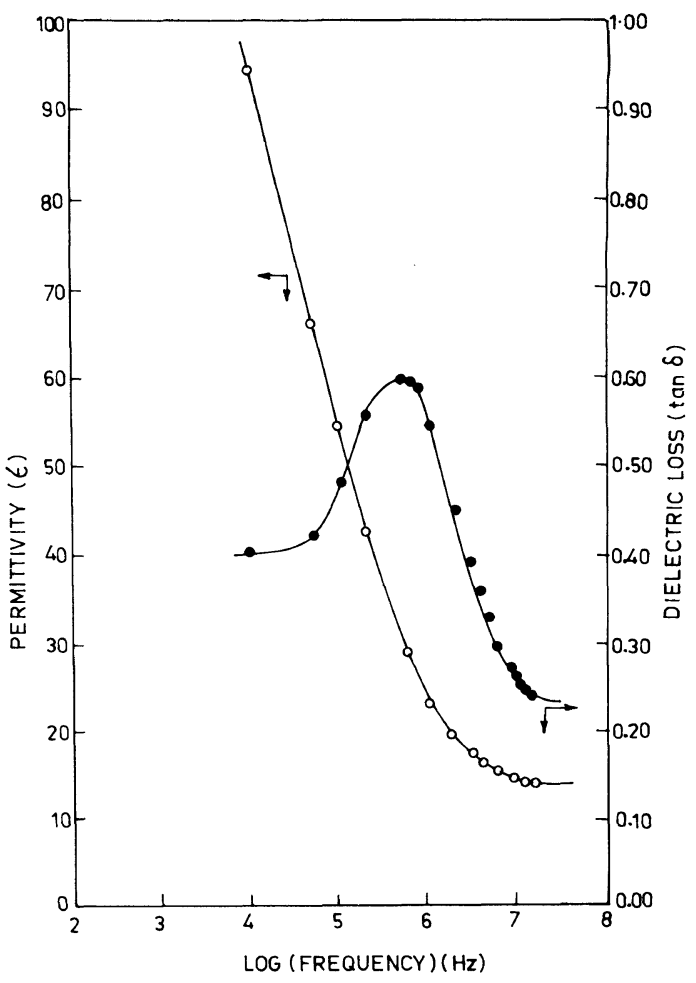

Figure 3. Dielectric behavior of CNPAD.

bonding facilitated by the presence of strong polar groups such as $-\mathrm{N}=\mathrm{N}-,-\mathrm{SO}_{3} \mathrm{H}$ and $-\mathrm{OH}$ and orientation polarization are believed $^{7}$ to be more significant at lower field frequency and is responsible for the major increase in $\tan \delta$. At higher electric field frequency, hydrogen bonding is expected to be weak and less stable and thereby the contribution by orientation polarization will decrease.

\section{Conductivity Characteristics}

In the temperature range $23^{\circ} \mathrm{C}$ to $160^{\circ} \mathrm{C}$, the d.c. conductivity of CNPAD varies from $10^{-8}$ to $10^{-6} \mathrm{ohm}^{-1} \mathrm{~cm}^{-1}$. The thermal activation energy (Figure 4) for conduction is calculated to be $0.74 \mathrm{eV}$. The $\Delta E$ values (Table III) for a number of monomeric diazo derivatives of naphthalene bearing $-\mathrm{OH},-\mathrm{SO}_{3} \mathrm{H}$ moieties fall in the range $2.50-1.00 \mathrm{eV}^{2}$. Sulfo groups usually enhance an intermolecular transport

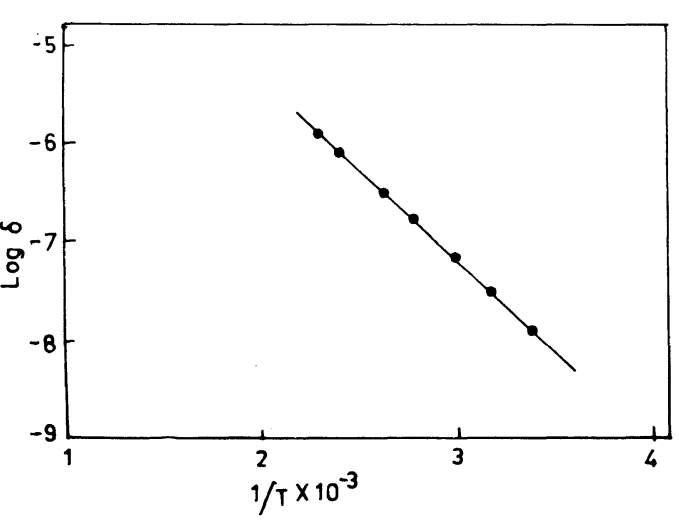

Figure 4. $\log$ (conductivity) $/(1 / T)$ plot for CNPAD.

Table III. Conductivity values of different polymers

\begin{tabular}{lcc}
\hline & \multicolumn{1}{c}{ Conductivity } & \\
\cline { 2 - 2 } Compounds & References \\
\hline $\begin{array}{l}\text { CNPAD } \\
\text { Azodye containing }\end{array}$ & $10^{-8}-10^{-6}$ & This work \\
$-\mathrm{N}=\mathrm{N}-,-\mathrm{SO}_{3} \mathrm{H}$ and & $1.10^{-7}-2.10^{-6}$ & 2 \\
$-\mathrm{OH}$ group & $10^{-12}-10^{-15}$ & 2 \\
$\begin{array}{l}\text { Polyazodiphenylene } \\
\text { and polyazomethoxy } \\
\text { phenylene }\end{array}$ & $\left(\right.$ at $\left.100^{\circ} \mathrm{C}\right)$ & \\
$\begin{array}{l}\text { Polynaphthalenes } \\
\begin{array}{l}\text { Polyvinyl carbazole } \\
\text { Polycondensed product of } \\
\text { diazo-aromatic diamine } \\
\text { with quinones }\end{array}\end{array}$ & $\begin{array}{c}10^{-10} \\
<10^{-16}\end{array}$ & 2 \\
\hline
\end{tabular}

by forming intermolecular hydrogen bonds and causing higher conductivity and consequently low $\Delta E$ values. $^{2,4}$ Moreover, $\Delta E$ decreases with an increase in the size of the molecule. ${ }^{2}$ In addition, delocalization of the $\pi$ electrons over the entire structure with conjugated double bonds also helps to achieve a very high conductivity and consequently a low $\Delta E$ values. $^{2,9}$ Thus in CNPAD, conjugation is strongly favored through the heterocyclic (carbazole) and the naphthalene moiety containing $-\mathrm{SO}_{3} \mathrm{H}$ and $-\mathrm{OH}$ groups as well as the $-\mathrm{N}=$ $\mathrm{N}$ - group. As such, the high conductivity and low $\Delta E$ values are reasonable. 


\section{CONCLUSIONS}

Carbazole based polymeric azodye bearing the naphthalene moiety exhibits higher overall thermal stability than the corresponding dye carrying bisphenol-A moiety. These dyes exhibit d.c. conductivity in the range $10^{-8}$ $10^{-6} \mathrm{ohm}^{-1} \mathrm{~cm}^{-1}$ which falls nearly in the semiconductor range. They behave as high loss polymers with dielectric constants falling sharply with frequency.

Acknowledgement. We thank the C.S.I.R., New Delhi for sponsoring a research project and the authorities of I.I.T., Kharagpur for facilities.

\section{REFERENCES}

1. M. Biswas and S. K. Das, Polymer, 23, 1713 (1982).

2. H. Meier, "Organic Semiconductors," Vol. 2, Verlag Chemie, Weinheim, 1974, pp 209-238 (also p 148).

3. M. Biswas and S. K. Das, J. Polym. Sci., Polym. Chem. Ed., 19, 3155 (1981).

4. A. I. Vogel, "A Textbook of Quantitative Inorganic Analysis," Longmans-Green, London, 1962.

5. A. I. Vogel, "A Textbook of Practical Organic Chemistry," Longmans-Green, London, 1959.

6. I. L. Finar, "Organic Chemistry," Vol. I, LongmansGreen, London, 1973, p 885.

7. A. D. Jenkins, "Polymer Science," North-Holland, London, 1972, pp 1233-1237.

8. A. Tager, "Physical Chemistry of Polymers," Mir, Moscow, 1972, pp 273-286.

9. H. W. Gibsor, "New Monomers and Polymers," Vol. 25, M. M. Culbertson and C. U. Pittman, Jr. ed, Plenum Series, New York and London, 1984, pp $381-398$. 